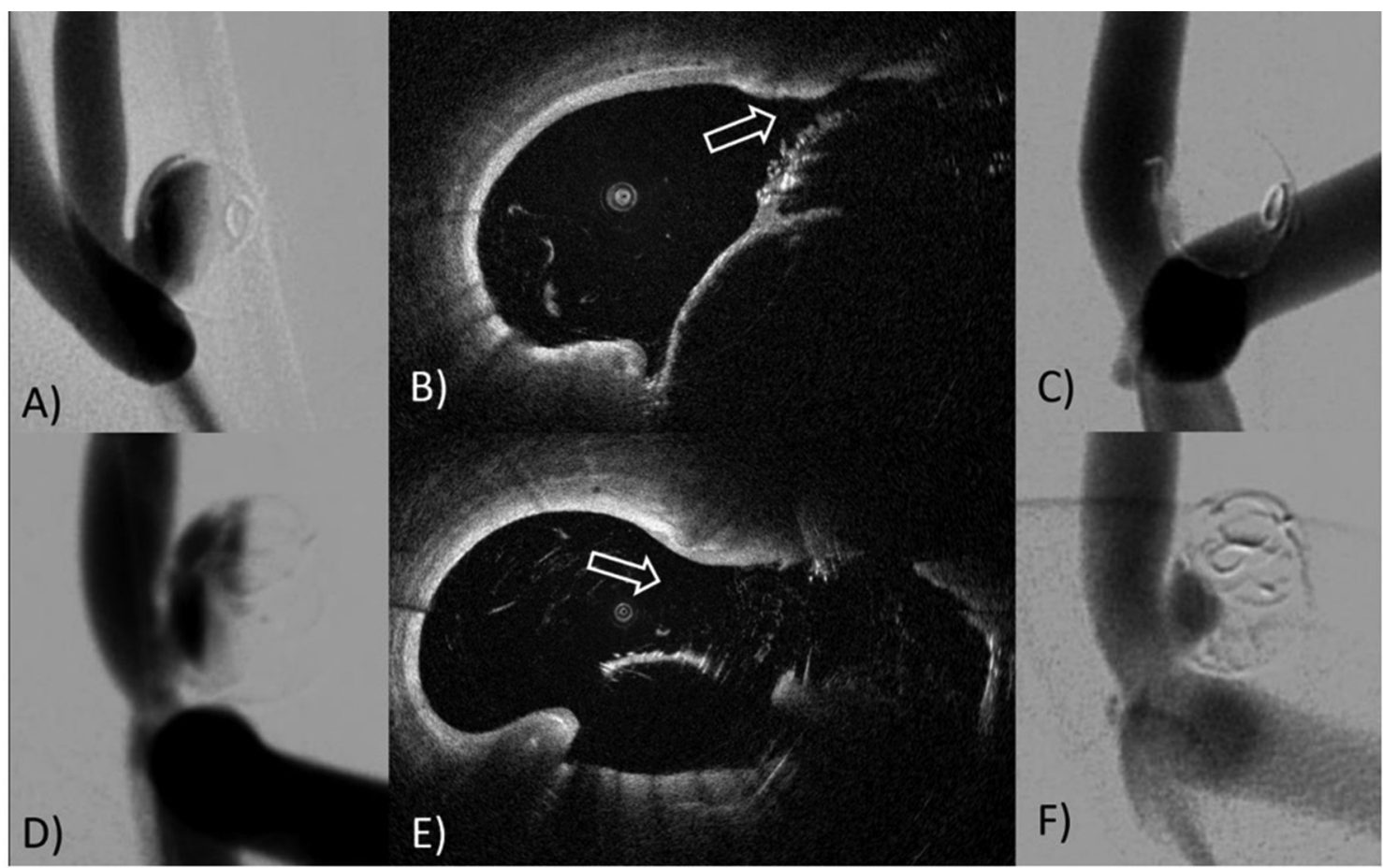

Abstract P-020 Figure 1 The upper panels show implant DSA (A), implant HF-OCT cross-sectional imaging, with the device visible between 1 and 6 o'clock (B), and 180-day final DSA (C), for an animal with a small gap in the construct (white arrow, B). The device successfully healed at 180-day DSA. The lower panels show implant DSA (D), implant HF-OCT cross-sectional imaging (aneurysm neck between 2 and 6 o'clock) (E), and 180-day DSA (F) for an animal with a large gap in the construct (white arrow, E). In this case, the device remained open at 180-day final DSA.

Abstract P-020 Table 1 largest coverage gap in the NGID construct as it compares to the implant and final DSA occlus

\begin{tabular}{lllll}
\hline $\begin{array}{l}\text { Animal } \\
\text { number }\end{array}$ & Location & $\begin{array}{l}\text { Implant } \\
\text { DSA score }\end{array}$ & $\begin{array}{l}\text { Largest coverage gap at } \\
\text { implant }\left(\mathbf{m m}^{2}\right)\end{array}$ & $\begin{array}{l}\text { 180-D DSA } \\
\text { outcome score }\end{array}$ \\
\hline Animal 2 & Bifurcation & 3 & 1.57 & 3 \\
Animal 3 & Bifurcation & 3 & 0.18 & 1 \\
Animal 4 & Sidewall & 2 & 0.55 & 1 \\
Animal 4 & Bifurcation & 3 & 1.30 & 3 \\
Animal 5 & Sidewall & 3 & 0.09 & 1 \\
Animal 6 & Sidewall & 3 & 0.08 & 1 \\
Animal 6 & Bifurcation & 3 & 0.12 & 1 \\
\hline
\end{tabular}

Disclosures R. King: None. M. Marosfoi: None. J. Caroff: None. G. Ughi: 4; C; Gentuity LLC. 5; C; Gentuity LLC. D. Groth: None. M. Gounis: None. A. Puri: None.

\section{P-021 COMFORT- COLOMBIAN MULTICENTER FLOW-DIVERTER OBSERVATIONAL RECONSTRUCTION TRIAL. LOCAL EXPERIENCE IN THE ENDOVASCULAR TREATMENT OF INTRACRANIAL ANEURYSMS WITH FRED STENT}

${ }^{1}$ B Pabon*, 'C Diaz, ${ }^{2} \mathrm{M}$ Fonseca, ${ }^{3} \mathrm{~N}$ Lobelo, ${ }^{4} \mathrm{~J}$ Holguin, ${ }^{1} \mathrm{~J}$ Mejia, ${ }^{1} \mathrm{O}$ Vargas, ${ }^{1} \mathrm{M}$ Patiño, ${ }^{1} \mathrm{~N}$ Serna. ${ }^{1}$ Neuroendovascular Surgery, Angioteam - Clinica del Norte, Medellin, Colombia; ${ }^{2}$ Neuroendovascular Surgery, unipamplona. medinorte, Cucuta, Colombia; ${ }^{3}$ Neuroendovascular Surgery, Clinica Colombia, bogota, Colombia; ${ }^{4}$ Neuroendovascular Surgery, Clinica Imbanaco, Cali, Colombia

10.1136/neurintsurg-2019-SNIS.57
Purpose Flow-diverting stents, such as the Flow Re-direction Endoluminal Device (FRED; MicroVention, Tustin, California, USA), have emerged as a novel means of treating complex intracranial aneurysms. This observational analysis of the initial Colombian experience provides insight into patient selection, technical challenges, clinical and radiographic outcomes, and complication rates after the use of FRED device for intracranial aneurysms.

Materials and methods Cases were compiled from 5 Colombian centers between March 2014 and April 2017. We performed a multicenter study evaluating patients with intracranial aneurysms treated with FRED. Technical success, morbidity and mortality were registered. Regarding safety, a well-defined variables included: spontaneous rupture of the FRED-treated aneurysm; spontaneous nonaneurysmal or distal intracranial hemorrhage (ICH); thrombo- embolic stroke; parent artery stenosis, and permanent cranial neuropathy.

Results During the defined study period, 252 patients with 268 aneurysms treated with FRED were included in this registry. Technical success stent deployment observed in all cases with exception of two cases where the operators decided to pull back the device and treated the aneurysms with other strategy. The mean aneurysm size was $12.4 \pm 5 \mathrm{~mm}$, and the median angiographic follow-up was 11.5 months. 81 aneurysms (30.2\%) were small, $132(49.2 \%)$ were large and 55 $(20.5 \%)$ were giant. The median clinical follow-up time was 16 months. The neurological morbidity rate was 7.5\% (19/ $252)$, and the neurological mortality rate was $2.3 \%(6 / 252)$. The combined neurological morbidity/mortality rate was $9.8 \%$. The most common adverse events were ischemic stroke $(5.9 \%, 15 / 252)$ and spontaneous ICH $(1.9 \%, 5 / 252)$. The complete occlusion rate at the last follow-up was $87.6 \%$ (92/ 105). 
Conclusion In the largest regional series on FRED for intracranial aneurysms to date, data suggest that treatment with the Flow Re-direction Endoluminal Device is safe and efficacious, with complication rates comparable with others FD available. Our local results are promising but larger series with longterm follow-up are required to determine its superiority.

Disclosures B. Pabon: 2; C; Microvention, Medtronic, Stryker. C. Diaz: None. M. Fonseca: None. N. Lobelo: None. J. Holguin: None. J. Mejia: None. O. Vargas: None. M. Patiño: None. N. Serna: None.

\section{P-022 IMPACT OF WEB ON PROCEDURE TIMES, ANESTHESIA AND RADIATION FOR TREATMENT OF WIDE NECK BIFURCATION ANEURYSMS}

A Rai ${ }^{*}$, R Turner, S Boo. Interventional Neuroradiology, West Virginia University, Morgantown, WV

\subsection{6/neurintsurg-2019-SNIS.58}

Objective The approval of WEB adds another option for treatment of wide neck bifurcation (WNB) aneurysms. The objective of this study was to compare the procedure times and radiation dose when using WEB versus stent-coil for WNB aneurysms in our early experience.

Methods

Four procedure variables were analyzed Operating room (OR) time was the duration from patient room arrival to room exit. Anesthesia time was from intubation to extubation. Procedure time was from groin puncture to closure. Radiation exposure was the fluoroscopy time and radiation dose for each procedure. All these were obtained from the procedure logs for 22 patients treated with WEB and 21 patients consecutively treated prior to WEB with stent-coiling. Patients with aneurysms greater than $10 \mathrm{~mm}$ in average width were excluded to level the comparison as larger aneurysms requiring more coils could take longer and the upper width size limit for WEB is currently at $10 \mathrm{~mm}$.

Results The average width and height of the aneurysms in the two cohorts was similar (Width $=5.9( \pm 2.2) \mathrm{mm}$ for the stentcoil versus $5.2( \pm 1.6) \mathrm{mm}$ for the WEB-group, $\mathrm{p}=0.2$; Height $=6.8( \pm 3.1) \mathrm{mm}$ for the stent-coil versus $5.8( \pm 1.7) \mathrm{mm}$ for the WEB-group, $p=0.2$ ). The OR, anesthesia and procedure times were significantly lower in the WEB-group compared to the stent-coil group (figure-1). The fluoroscopy time and the radiation dose was also significantly lower in the WEB-group versus the stent-coil group (figure-1).

Conclusion The use of WEB in WNB aneurysms significantly reduced OR, anesthesia and procedure times versus stent-coiling for similar sized aneurysms. Radiation dose and fluoroscopy times were also significantly reduced. For the WEB group these times are expected to be independent of aneurysm size whereas stent-coiling may be associated with longer times for larger aneurysms.

Disclosures A. Rai: 2; C; MicroVention, Stryker. R. Turner: None. S. Boo: 2; C; Stryker.

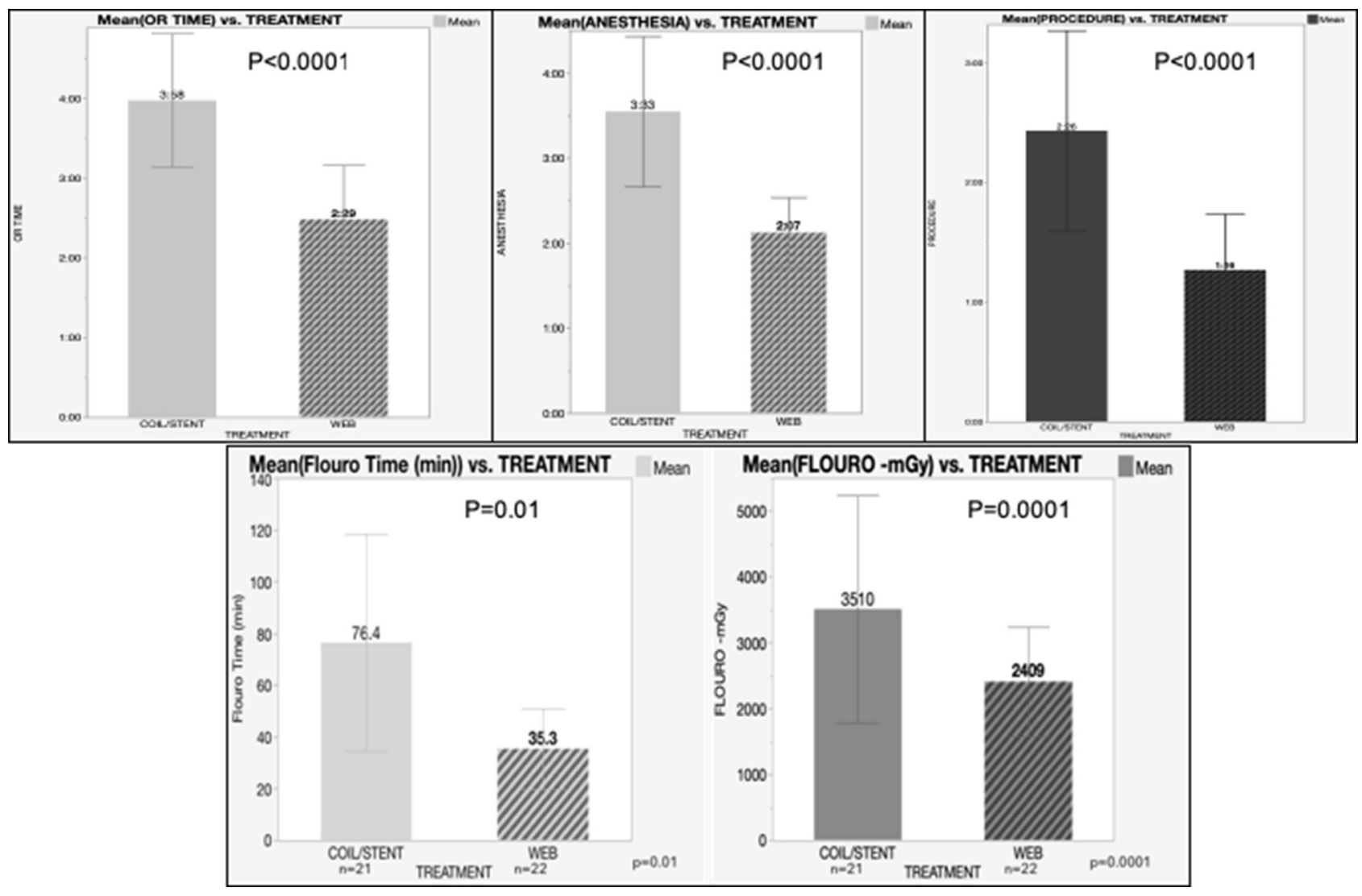

Abstract P-022 Figure 1 